Check for updates

Cite this: New J. Chem., 2017, 41,9216

Received 16th June 2017, Accepted 21st July 2017

DOI: 10.1039/c7nj02165h

rsc.li/njc

\title{
Particle size, morphology and phase transitions in hydrothermally produced $\mathrm{VO}_{2}(\mathrm{D}) \dagger$
}

\author{
Diana Teixeira, (D) ${ }^{\text {ab }}$ Raul Quesada-Cabrera, ${ }^{a}$ Michael J. Powell, ${ }^{a}$ G. K. L. Goh, \\ G. Sankar, ${ }^{a}$ I. P. Parkin (D) a and R. G. Palgrave*a
}

\begin{abstract}
Different morphologies and sizes of $\mathrm{VO}_{2}(\mathrm{D})$ particles were synthesised via hydrothermal synthesis using ammonium metavanadate $\left(\mathrm{NH}_{4} \mathrm{VO}_{3}\right)$ or vanadium pentoxide $\left(\mathrm{V}_{2} \mathrm{O}_{5}\right)$ as a vanadium precursor. By adjusting the concentration of vanadium precursors and the $\mathrm{pH}$ of the starting solution, a variety of morphologies and sizes of $\mathrm{VO}_{2}(\mathrm{D})$ particles from $20 \mathrm{~nm}$ to $3 \mu \mathrm{m}$ could be produced. A flower-shape morphology was obtained under strongly acidic conditions, passing through star-shape particles of $1 \mu \mathrm{m}$ at $\mathrm{pH} 2.5$ and finally obtaining homogeneous round balls of around $3 \mu \mathrm{m}$ at $\mathrm{pH}$ 6.9. Nanoparticles were produced hydrothermally using $\mathrm{V}_{2} \mathrm{O}_{5}$ as a precursor and hydrazine as a reducing agent. The transition from $\mathrm{VO}_{2}(\mathrm{D})$ to thermochromic $\mathrm{VO}_{2}(\mathrm{R})$ in micron scale particles occurred at $350{ }^{\circ} \mathrm{C}$ under vacuum. However, the nanoparticles of $\mathrm{VO}_{2}(\mathrm{D})$ had a significantly lower $\mathrm{VO}_{2}(\mathrm{D})$ to thermochromic $\mathrm{VO}_{2}(\mathrm{R})$ transition temperature of $165{ }^{\circ} \mathrm{C}$ after annealing for only a few minutes. This is, to our knowledge, the lowest annealing temperature and time reported in the literature in order to obtain a thermochromic $\mathrm{VO}_{2}$ material via another $\mathrm{VO}_{2}$ phase. After the conversion of $\mathrm{VO}_{2}(\mathrm{D})$ microparticles to thermochromic $\mathrm{VO}_{2}(\mathrm{R})$, the metal to insulator transition temperature is $61 \pm 1^{\circ} \mathrm{C}$ for the heating cycle and $53 \pm 1{ }^{\circ} \mathrm{C}$ for the cooling cycle. However, $\mathrm{VO}_{2}(\mathrm{R})$ nanoparticles showed a significantly reduced metal insulator transition temperature of $59 \pm 1{ }^{\circ} \mathrm{C}$ and $42 \pm 1{ }^{\circ} \mathrm{C}$ for the cooling cycle lower than that reported in the literature for bulk $\mathrm{VO}_{2}$. This is important due to the need for having a compound with a switching temperature closer to room temperature to be used in smart window devices for energy consumption. $\mathrm{W}-\mathrm{VO}_{2}(\mathrm{D})$ star shape microparticle samples were prepared using 2-7 at\% of the dopant (using ammonium metavanadate as a precursor), although unexpectedly this does not seem to be a viable route to a reduced metal to insulator transition in this system.
\end{abstract}

\section{Introduction}

$\mathrm{VO}_{2}$ has been investigated for a wide range of technological applications, including optical and electrical switching devices, multifunctional spintronics, ${ }^{1}$ IR sensors and vision equipment, as coatings to prevent detection by reducing the IR transmittance of blackbody emitters, ${ }^{2}$ to missile seeker sensors, and various other applications. ${ }^{3} \mathrm{VO}_{2}$ nanorods have been used to prepare Li-ion batteries with a discharge capacity of $152 \mathrm{~mA} \mathrm{~h} \mathrm{~g}{ }^{-1}$. $^{4}$ W-Doped $\mathrm{VO}_{2}(\mathrm{~B})$ nanobelts are used in supercapacitors. ${ }^{5} \mathrm{VO}_{2}$ nano-flowers were synthesized by Kang et al. for energy-storage devices and supercapacitors. ${ }^{6} \mathrm{TiO}_{2} / \mathrm{VO}_{2}$ nanofibers are reported to photocatalyze the degradation of pollutants from wastewater by Zhao et al. ${ }^{7} \mathrm{VO}_{2}(\mathrm{~B})$ nanosheets were fabricated as a cathode

\footnotetext{
${ }^{a}$ Department of Chemistry, Materials Chemistry Centre, University College London, 20 Gordon St., London WC1H 0AJ, UK. E-mail: r.palgrave@ucl.ac.u

${ }^{b}$ Institute of Materials Research and Engineering, Agency for Science, Technology and Research ( $A^{*}$ STAR), 2 Fusionopolis Way, Singapore 138634, Singapore

$\dagger$ Electronic supplementary information (ESI) available. See DOI: 10.1039/c7nj02165h
}

electrode presenting a high initial discharge and stable cyclability compared to bulk $\mathrm{VO}_{2}(\mathrm{~B})$ as Want et al. reported in their work. ${ }^{8}$

$\mathrm{VO}_{2}$ has also been widely studied for architectural applications due to its thermochromic properties: $\mathrm{VO}_{2}$ displays a reversible phase transition from a low temperature, monoclinic insulating phase, $\mathrm{VO}_{2}(\mathrm{M})$ to a high temperature, rutile, metallic phase, $\mathrm{VO}_{2}(\mathrm{R})$ at $68{ }^{\circ} \mathrm{C}$. ${ }^{9}$ This metal to semiconductor phase transition (MST) is associated with an increase in reflectivity in the near infrared which has led to the use of $\mathrm{VO}_{2}$ as a thermochromic material, able to change its optical properties with temperature. Specifically, $\mathrm{VO}_{2}$ films coated onto windows can actively switch between a high IR transmittance state below the MST temperature to a low IR transmittance state above the MST temperature.

The transition temperature of undoped $\mathrm{VO}_{2}(\mathrm{M})$ is $68{ }^{\circ} \mathrm{C}$, which is too high for solar control coating applications. The transition temperature, however, can be reduced by doping with $\mathrm{W}, \mathrm{Ti}, \mathrm{Mg}$ or other ions; $\mathrm{W}$ doping is the most effective dopant, with a reduction of $\sim 25{ }^{\circ} \mathrm{C}$ per at\% $\mathrm{W}$ incorporated. Therefore, doping is seen as an effective method to achieve 
$T_{\mathrm{c}}$ in the optimum range for thermochromic windows. ${ }^{10-12}$ Being able to reduce the phase transition temperature, towards room temperature, would allow for the maximum energy saving potential of solar control coatings.

Vanadium dioxide $\left(\mathrm{VO}_{2}\right)$ has a well-known range of stable phases, such as $\mathrm{VO}_{2}(\mathrm{M})$ and $\mathrm{VO}_{2}(\mathrm{R})$, as well as metastable phases, such as $\mathrm{VO}_{2}(\mathrm{~A}), \mathrm{VO}_{2}(\mathrm{~B})$ and $\mathrm{VO}_{2}(\mathrm{C}){ }^{13,14}$ Most of these phases consist of octahedrally coordinated $\mathrm{V}^{4+}$ ions with different linkages of octahedra leading to different crystal structures. ${ }^{15}$ $\mathrm{VO}_{2}(\mathrm{~A})$ has a MST temperature of $162{ }^{\circ} \mathrm{C}$. The solid has a good thermal stability and oxidation resistance in air below $408{ }^{\circ} \mathrm{C}^{16}$ $\mathrm{VO}_{2}(\mathrm{~B})$ has been commonly used as a convenient route to achieving the $\mathrm{VO}_{2}(\mathrm{M})$ phase by annealing at $450{ }^{\circ} \mathrm{C}$ or above under an inert atmosphere. ${ }^{17}$

$\mathrm{VO}_{2}(\mathrm{D})$ is a newly discovered meta-stable phase ${ }^{17,18}$ that has gained attention in the $\mathrm{VO}_{2}$ field as it allows the direct transition to $\mathrm{VO}_{2}(\mathrm{M})$ at relatively low temperatures $\left(250-400{ }^{\circ} \mathrm{C}\right) .{ }^{13,18}$ Moreover, once the monoclinic phase is obtained from the $\mathrm{VO}_{2}(\mathrm{D})$ phase, the MST temperature of the resulting $\mathrm{VO}_{2}(\mathrm{M})$ material is lower $\left(61^{\circ} \mathrm{C}\right)$ than that widely reported in the literature $\left(68^{\circ} \mathrm{C}\right) .{ }^{13}$

$\mathrm{VO}_{2}$ can be produced from a wide range of methods, including atmospheric pressure chemical vapour deposition (APCVD), ${ }^{10,19}$ sputtering and spin coating ${ }^{20}$ and, continuous hydrothermal flow synthesis $^{21}$ (CHFS) and hydrothermal synthesis ${ }^{22}$ among others. Nevertheless, the challenge to find an easy, scalable and affordable process to produce $\mathrm{VO}_{2}(\mathrm{M})$ at low temperatures remains. A new approach to obtain $\mathrm{VO}_{2}(\mathrm{M})$ in one step via hydrothermal synthesis has been reported recently; ${ }^{11,22}$ however the process is not easily reproducible due to the strict control required over experimental conditions such as temperature, pressure, time, $\mathrm{pH}$, etc.

Here we report the synthesis of the $\mathrm{VO}_{2}(\mathrm{D})$ phase. A range of particle sizes, from nano- to micro-particles, were observed. The particle size and shape could be easily tailored by varying the $\mathrm{pH}$; furthermore, when in the form of nanoparticles, the $\mathrm{VO}_{2}(\mathrm{D})$ to $(\mathrm{M})$ phase transition could be achieved at annealing temperatures as low as $165^{\circ} \mathrm{C}$, significantly lower that previous reports on the $\mathrm{VO}_{2}(\mathrm{D})$ to $(\mathrm{M})$ phase transformation $\left(\mathrm{ca} .400{ }^{\circ} \mathrm{C}\right)$. Moreover, the $\mathrm{VO}_{2}(\mathrm{R})$ particles thus produced show a lower thermochromic transition temperature than expected for bulk vanadium dioxide. Finally we highlight the importance of particle size in controlling the phase behaviour of this important material. The advantages of producing nanoparticles of $\mathrm{VO}_{2}$ are that they can give superior luminous transmittance and solar energy transmittance modulation compared to $\mathrm{VO}_{2}$ films, as is reported in the literature by S.-Y. Li et $a l^{23}$

\section{Experimental section}

\subsection{Synthesis of $\mathrm{VO}_{2}(\mathrm{D})$ microparticles}

All reagents were obtained from Sigma Aldrich except for sodium hydroxide which was purchased from Alfa Aesar and were used without any further purification. In a typical reaction $0.625 \mathrm{~g}$ [0.0024 mol] of ammonium metavanadate $\left(\mathrm{NH}_{4} \mathrm{VO}_{3}\right)$, $2.52 \mathrm{~g}$ of oxalic acid $\left(\mathrm{C}_{2} \mathrm{H}_{2} \mathrm{O}_{4}\right)$ used as a reducing agent, and $0.5 \mathrm{~g}$ of polyvinylpyrrolidone (PVP) were mixed into $50 \mathrm{~mL}$ of
Table 1 Sample names and descriptions for $\mathrm{VO}_{2}$ powders synthesized by the reaction between $\mathrm{NH}_{4} \mathrm{VO}_{3}$ and $\mathrm{C}_{2} \mathrm{H}_{2} \mathrm{O}_{4}$ in water. $\mathrm{NaOH}$ was used to adjust the $\mathrm{pH}$ of the starting solution. All samples were synthesized via hydrothermal treatment for 24 hours at $220^{\circ} \mathrm{C}$

\begin{tabular}{ll}
\hline Sample & pH of the starting solution \\
\hline S01 & 0.65 \\
S02 & 0.98 \\
S03 & 1.05 \\
S04 & 1.52 \\
S05 & 2.5 \\
S06 & 3.51 \\
S07 & 4.6 \\
S08 & 5.5 \\
S09 & 6.91
\end{tabular}

deionized water under continuous stirring until a green solution was obtained, indicating the presence of $\mathrm{V}^{3}$ in the solution. The $\mathrm{pH}$ of the solution was adjusted using $\mathrm{NaOH}(1 \mathrm{M})$ (Table 1). Hydrothermal treatment was carried out using $27 \mathrm{~mL}$ of the resultant solution into a $45 \mathrm{~mL}$ Teflon lined autoclave and heated at $220{ }^{\circ} \mathrm{C}$ for 24 hours. Further studies were carried out using $\mathrm{W}$-doped $\mathrm{VO}_{2}$ (D) microparticles synthesised using 2-7 at\% of $\mathrm{WCl}_{4}$ (relative to the vanadium precursor) added to the initial solution. The reaction conditions were the same as used for the undoped samples. After hydrothermal synthesis, particles were filtered and washed with deionized water and ethanol.

\subsection{Synthesis of $\mathrm{VO}_{2}(\mathrm{D})$ nanoparticles}

To prepare $\mathrm{VO}_{2}(\mathrm{D})$ nanoparticles, $0.45 \mathrm{~g}[0.0024 \mathrm{~mol}]$ of vanadium pentoxide $\left(\mathrm{V}_{2} \mathrm{O}_{5}\right), 0.75 \mathrm{~mL}$ of sulfuric acid $\left(\mathrm{H}_{2} \mathrm{SO}_{4}\right)$ and $0.25 \mathrm{~mL}$ of hydrazine hydrate were added to $10 \mathrm{~mL}$ of deionized water and stirred for 3-5 minutes. The $\mathrm{pH}$ of the solution was adjusted to 6.6-6.9 using $\mathrm{NaOH}(1 \mathrm{M})$ and finally the solution was centrifuged to obtain a grey paste. The grey paste was dissolved in $19 \mathrm{~mL}$ of DI water and poured into a $45 \mathrm{~mL}$ teflon lined autoclave and heated to $240{ }^{\circ} \mathrm{C}$ for 48 hours. The product was isolated by centrifugation and washed with deionized water and ethanol.

In Table 2 the conditions used to prepare the $\mathrm{VO}_{2}(\mathrm{D})$ nanoparticles are stated. The $\mathrm{pH}$ range must be controlled within a narrow range to avoid an undesired phase. Three samples are presented here to show the $\mathrm{pH}$ range that can be used.

Table 2 Sample names and descriptions for $\mathrm{VO}_{2}$ powders synthesized by the reaction between $\mathrm{V}_{2} \mathrm{O}_{5}$ and $\mathrm{H}_{2} \mathrm{SO}_{4}$ in water. $\mathrm{NaOH}$ was used to adjust the $\mathrm{pH}$ of the solution. Samples were synthesized via hydrothermal synthesis for 48 hours at $240{ }^{\circ} \mathrm{C}$

\begin{tabular}{ll}
\hline Sample & pH of the starting solution \\
\hline S16 & 6.62 \\
S17 & 6.75 \\
S18 & 6.84
\end{tabular}

\subsection{Materials characterisation}

$\mathrm{X}$-ray diffraction studies were carried out using a D8 GADDS Bruker diffractometer, utilising $\mathrm{Cu} K \alpha$ radiation $(\lambda=1.541 \AA)$ between 10 and 60, 20. Field Emission Scanning Electron 
Microscopy (FESEM) analysis was performed using a JEOL JSM-6700Ff instrument with an accelerating voltage of $5 \mathrm{keV}$ and Transmission Electron Microscopy (TEM) analysis was performed using a Phillips CM300 FEG TEM, operated at $300 \mathrm{kV}$. Differential scanning calorimetry (DSC) analysis was obtained on a DSC 1 instrument from Mettler Toledo. These experiments were carried out between 0 and $300{ }^{\circ} \mathrm{C}$ under a controlled nitrogen atmosphere with a heating ramp of $5{ }^{\circ} \mathrm{C} \min ^{-1}$. Raman spectroscopy was performed using a Renishaw 1000 spectrometer with a $633 \mathrm{~nm}$ laser. The equipment was calibrated using a silicon reference.

\section{Results and discussion}

\section{1 $\mathrm{VO}_{2}$ powder characterization}

$\mathrm{VO}_{2}$ microparticles were produced through the hydrothermal reaction of ammonium metavanadate with oxalic acid in the presence of polyvinylpyrrolidone (PVP). Adjusting the $\mathrm{pH}$ of the initial reactant mixture with $1.0 \mathrm{M} \mathrm{NaOH}$ proved to be an easy and reproducible route to obtain microparticles of the $\mathrm{VO}_{2}(\mathrm{D})$ phase with different morphologies. The conditions used in the $\mathrm{VO}_{2}(\mathrm{D})$ microparticle synthesis are summarized in Table 1.

Fig. 1 shows the XRD pattern of the prepared $\mathrm{VO}_{2}(\mathrm{D})$ phase using $\mathrm{NH}_{4} \mathrm{VO}_{3}$ as a precursor with different $\mathrm{pH}$ values of the starting solution. All peaks shown in the as-prepared samples are indexed to the $\mathrm{D}$ phase of $\mathrm{VO}_{2}$. Fig. 1 presents the $\mathrm{VO}_{2}(\mathrm{D})$ pattern reported in the literature for comparison purposes. All the $\mathrm{VO}_{2}(\mathrm{D})$ peaks of the prepared samples match with the literature pattern. ${ }^{17}$

$\mathrm{VO}_{2}$ (D) nanoparticles (20-40 nm) were obtained by hydrothermal synthesis using $\mathrm{V}_{2} \mathrm{O}_{5}$, hydrazine hydrate and sulfuric acid as starting reagents. In this case, changing the $\mathrm{pH}$ appears to affect the phase of vanadium oxide produced rather than the morphology. $\mathrm{VO}_{2}(\mathrm{D})$ is formed only at $\mathrm{pH}$ between 6.6 and 6.9, outside this range, other phases, $\mathrm{VO}_{2}(\mathrm{~B})$ and $\mathrm{VO}_{2}(\mathrm{~A})$, or mixed phases of $\mathrm{VO}_{2}$ are obtained.

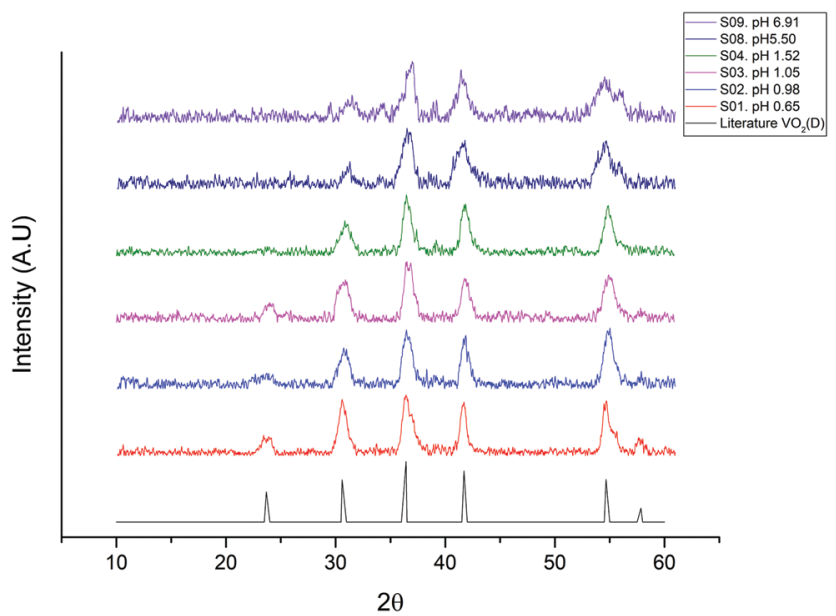

Fig. 1 XRD patterns of the $\mathrm{VO}_{2}(\mathrm{D})$ microparticles as synthesised from the ammonium metavanadate precursor under different $\mathrm{pH}$ conditions. A reference $\mathrm{XRD}$ pattern of $\mathrm{VO}_{2}(\mathrm{D})$ has been obtained from the literature. ${ }^{17}$

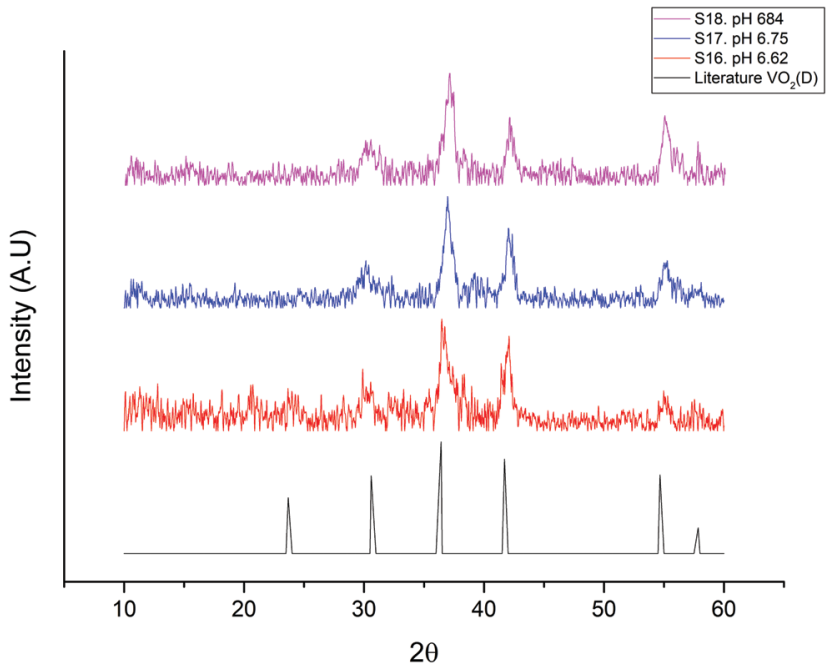

Fig. 2 XRD pattern of the prepared samples using vanadium pentoxide as a precursor and $\mathrm{NaOH}$ to adjust the $\mathrm{pH}$ of the solution. All peaks correspond to the $\mathrm{VO}_{2}(\mathrm{D})$ phase shown in the literature. ${ }^{17}$

Fig. 2 shows the XRD of three as-prepared samples of $\mathrm{VO}_{2}(\mathrm{D})$ nanoparticles with different $\mathrm{pH}$ values compared to the $\mathrm{VO}_{2}(\mathrm{D})$ pattern reported in the literature. ${ }^{17}$

Raman spectroscopy was performed for the as-prepared samples with different $\mathrm{pH}$ values of the starting solution. The result obtained in all cases was the typical Raman spectroscopy bands for $\mathrm{V}_{2} \mathrm{O}_{5} \cdot{ }^{24}$ When $\mathrm{VO}_{2}$ powder is exposed to air the surface of the sample tends to oxidize, thus when performing surface analysis as Raman, it is not unusual to obtain $\mathrm{V}_{2} \mathrm{O}_{5}$ in the results, which represent the $5+$ oxidation state, the most stable one. In this case, Raman spectroscopy bands show typical bands of $\mathrm{V}_{2} \mathrm{O}_{5}$, indicating that some degree of oxidation has taken place in our samples.

SEM images of the $\mathrm{VO}_{2}$ microparticles are shown in Fig. 3, as can be seen, increasing the $\mathrm{pH}$ of the starting solution without changing any other condition results in the growth of the particle size, and also a change in the morphology. At pH 0.65 a "flower shape" morphology made of small attached long particles is seen, while moving towards neutral $\mathrm{pH}$, larger smooth spheres are obtained.

In the present work ammonium metavanadate reacts with oxalic acid to produce vanadium(Iv) oxide, carbon monoxide and carbon dioxide as can be seen in eqn (1)-(3), this solution have an acid $\mathrm{pH}$, thus, small particle size, good homogeneity and low agglomeration are expected (and obtained in the as prepared samples):

$$
2 \mathrm{NH}_{4} \mathrm{VO}_{3}+4 \mathrm{C}_{2} \mathrm{H}_{2} \mathrm{O}_{4} \rightarrow\left(\mathrm{NH}_{4}\right)_{2}\left[(\mathrm{VO})_{2}\left(\mathrm{C}_{2} \mathrm{O}_{4}\right)_{3}\right]+2 \mathrm{CO}_{2}+4 \mathrm{H}_{2} \mathrm{O}
$$

$$
\left(\mathrm{NH}_{4}\right)_{2}\left[(\mathrm{VO})_{2}\left(\mathrm{C}_{2} \mathrm{O}_{4}\right)_{3}\right] \rightarrow 2 \mathrm{VOC}_{2} \mathrm{O}_{4}+2 \mathrm{NH}_{3}+\mathrm{CO}+\mathrm{CO}_{2}+\mathrm{H}_{2} \mathrm{O}
$$

$$
\mathrm{VOC}_{2} \mathrm{O}_{4} \rightarrow \mathrm{VO}_{2}+\mathrm{CO}+\mathrm{CO}_{2}
$$

However, when adding sodium hydroxide in the process to adjust the $\mathrm{pH}$ of the solution, we are also producing sodium 

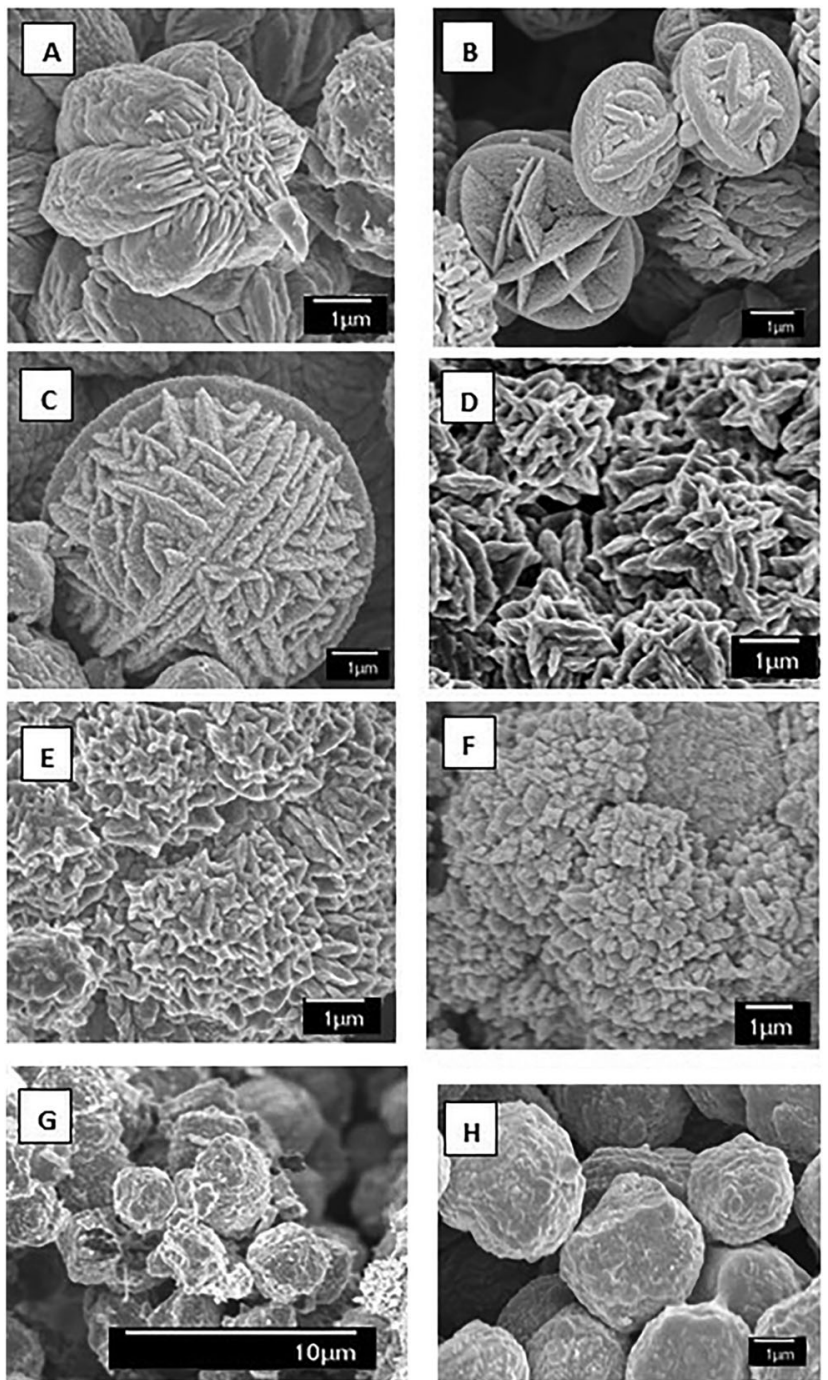

Fig. 3 SEM of the prepared samples using ammonium metavanadate as a precursor with different $\mathrm{pH}$ values: (A) 0.65 (B) 0.98 (C) 1.05 (D) 1.52 (E) 2.50 (F) $3.51(\mathrm{G}) 4.60$ (H) 6.91

orthovanadate, ammonia and water, as can be seen in eqn (4). This could affect the homogeneity of particles, due to greater agglomeration and growth of the particles. This explains the growth and the agglomeration of our particles due to the increase of the $\mathrm{pH}$ of the initial solution.

$$
\mathrm{NH}_{4} \mathrm{VO}_{3}+3 \mathrm{NaOH} \rightarrow \mathrm{Na}_{3} \mathrm{VO}_{4}+\mathrm{NH}_{3}+2 \mathrm{H}_{2}
$$

The change in the morphology and size by simply changing the $\mathrm{pH}$ is interesting as the $\mathrm{VO}_{2}(\mathrm{D})$ phase can be used for different applications depending on the morphology and size.

The $\mathrm{pH}$ of the starting precursor solution had a dramatic effect on the morphology observed in the synthesized $\mathrm{VO}_{2}$ particles Fig. 3. At a pH of 0.65, Fig. 3(A), a star/flower shape can be seen, similar to the desert rose formation of minerals. This morphology has been previously observed in other hydrothermally produced materials ${ }^{4,25}$ Increasing the $\mathrm{pH}$ of the starting solution to 0.98 , Fig. 3(B), causes the flower shape to disappear and a series of circular fused plates can be seen,
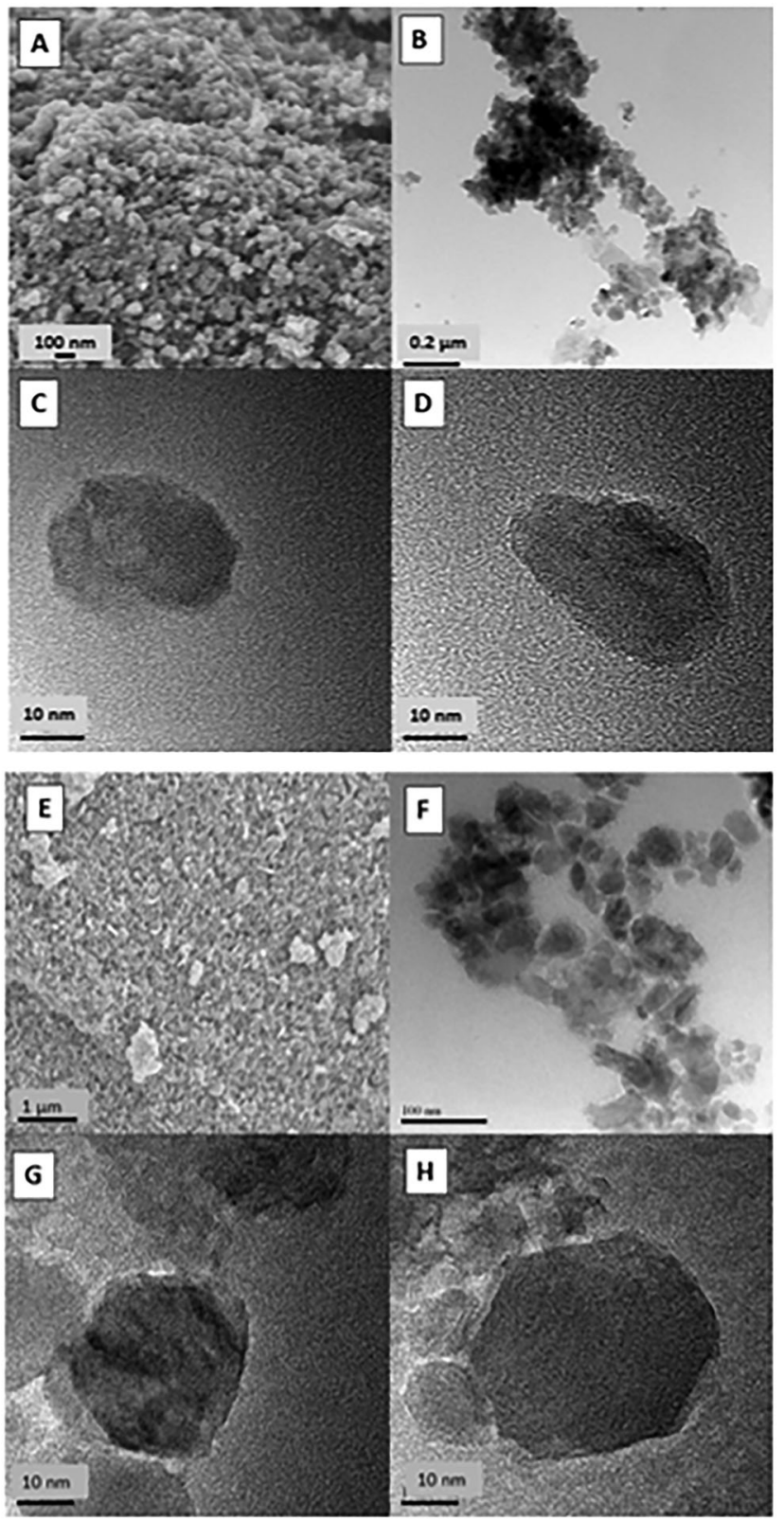

Fig. 4 (A) SEM image of sample 16 (B-D) TEM images of sample 16 (E) SEM image of sample $17(\mathrm{~F}-\mathrm{H})$ TEM images of sample 17.

apparently formed by small long particles well attached to one another, almost forming a solid sphere. At a $\mathrm{pH}$ of 1.05, Fig. 3(C), the particles appear to be more spherical, with ridges present on the surface of the particles. Further increasing the pH to 1.52, Fig. 3(D), results in the formation of small crossshape structures that are well defined can be seen to overlap to form larger structures. At a pH of 2.50, Fig. 3(E), the individual well-defined structures can still be seen; however it seems like their growth rate has being retarded. At $\mathrm{pH}$ values above 3.5, the particle shapes become more homogeneous, eventually adopting a sphere like shape. This can be seen in Fig. 3(F-H), where the higher $\mathrm{pH}$ of the starting precursor solution can be clearly seen to prevent the formation of smaller crystallite structures. 
Particle sizes range from $1 \mu \mathrm{m}$ at the most acidic $\mathrm{pH}$ to $\sim 4 \mu \mathrm{m}$ when $\mathrm{pH}$ is close to neutral. It is interesting that the morphology in most of the cases has a round shape but always present a "Ball-shape" made of small long rods attached; the round shape can be attributed to the use of PVP as this has been reported as a crystal growth modifier. ${ }^{17}$ The presence of PVP in this experiments seems to be essential in the formation of the $\mathrm{VO}_{2}(\mathrm{D})$ phase as reported by Liu Liang et al; ${ }^{17}$ if no PVP is added the product shows a pure $\mathrm{VO}_{2}(\mathrm{~B})$ phase.

The nanoparticles of $\mathrm{VO}_{2}(\mathrm{D})$ were prepared using $\mathrm{V}_{2} \mathrm{O}_{5}$ as a precursor. In Fig. 4 SEM and TEM images of the as-prepared samples can be seen. The particle size is around $20-40 \mathrm{~nm}$ and presents mainly a round shape. The $\mathrm{VO}_{2}(\mathrm{D})$ nanoparticles do not show any growth after heat treatment to convert to $\mathrm{VO}_{2}(\mathrm{R})$, meaning that the final products remain as nanoparticles.

Hydrazine is well known to promote nanoparticle formation as it can coordinate to metal ions during hydrothermal synthesis. ${ }^{26}$ Hence we believe that hydrazine plays a critical role in the production of $\mathrm{VO}_{2}(\mathrm{D})$ nanoparticles here.

\subsection{Functional properties}

The typical approach to obtain $\mathrm{VO}_{2}(\mathrm{R})$ for thermochromic applications is by annealing the $\mathrm{VO}_{2}(\mathrm{~B})$ phase under vacuum at temperatures that range between 420 and $700{ }^{\circ} \mathrm{C} .{ }^{27,28}$ The actual transformation temperature depends on the morphology of the $\mathrm{VO}_{2}$ (B) particles; we noticed in this work that nanoparticles of $\mathrm{VO}_{2}(\mathrm{D})$ require less time/temperature to transform into $\mathrm{VO}_{2}(\mathrm{M})$ than $\mathrm{VO}_{2}(\mathrm{D})$ microparticles. Importantly, the $\mathrm{VO}_{2}(\mathrm{D})$ phase can be converted to thermochromic $\mathrm{VO}_{2}(\mathrm{R})$ by thermal treatment at temperatures as low as $250{ }^{\circ} \mathrm{C}^{29}$ This is highly significant, as low temperature conversion allows preservation of the nanostructure of the parent phase, and as mentioned before, nanostructures show superior luminous transmittance and solar energy transmittance modulation, with this being a key point of the production of thermochromic $\mathrm{VO}_{2}$. The nano and microparticles produced in this work showed a significantly different phase transition behaviour. DSC was attempted to study the $\mathrm{VO}_{2}(\mathrm{D}) \rightarrow \mathrm{VO}_{2}(\mathrm{R})$ transition in our microparticles. However, the maximum temperature of our DSC was $300{ }^{\circ} \mathrm{C}$, and the desired transition did not occur in this temperature range. It was found that by annealing under vacuum the $\mathrm{VO}_{2}(\mathrm{D}) \rightarrow \mathrm{VO}_{2}(\mathrm{M})$ transition occurred in our microparticles at around $350{ }^{\circ} \mathrm{C}$. Once converted to thermochromic $\mathrm{VO}_{2}(\mathrm{R})$, cooling to room temperature will cause a further transition to $\mathrm{VO}_{2}(\mathrm{M})$. This $\mathrm{VO}_{2}(\mathrm{M})$ material was then subjected to DSC to study the $\mathrm{VO}_{2}(\mathrm{M}) \rightarrow \mathrm{VO}_{2}(\mathrm{R})$ transition, and the results are shown in Fig. 5. All studied samples present the same $T_{\mathrm{c}}$ to within $5{ }^{\circ} \mathrm{C}$ and for convenience only two samples are shown. As is shown in Fig. 5 there is a slight difference between the critical temperature for each sample, this may be due to morphology. In general the $T_{\mathrm{c}}$ is at $61 \pm 3{ }^{\circ} \mathrm{C}$ for the heating cycle and $55 \pm 2{ }^{\circ} \mathrm{C}$ for the cooling cycle, thus the thermal hysteresis width calculated from DSC is $6 \pm 1{ }^{\circ} \mathrm{C}$.

Reported DSC in the literature of $\mathrm{VO}_{2}(\mathrm{R})$ obtained in one step via hydrothermal synthesis shows a $T_{\mathrm{c}}$ temperature at

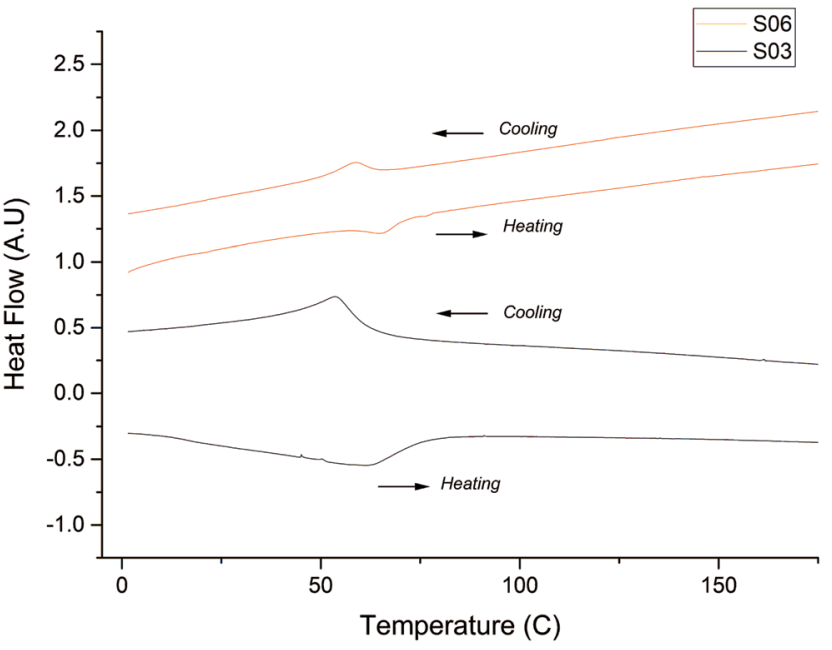

Fig. 5 DSC curves of $\mathrm{VO}_{2}(\mathrm{R})$ obtained via micro- $\mathrm{VO}_{2}(\mathrm{D})$ after heat treatment.

$65{ }^{\circ} \mathrm{C}$ for the heating cycle and $53.5{ }^{\circ} \mathrm{C}$ for the cooling sample, ${ }^{30}$ while samples of $\mathrm{VO}_{2}(\mathrm{R})$ obtained via $\mathrm{VO}_{2}(\mathrm{~A})$ using the hydrothermal synthesis method have a $T_{\mathrm{c}}$ for the heating cycle of $69{ }^{\circ} \mathrm{C}$ and $61{ }^{\circ} \mathrm{C}$ for the cooling sample. ${ }^{31}$ Samples of $\mathrm{VO}_{2}(\mathrm{R})$ obtained via $\mathrm{VO}_{2}(\mathrm{D})$ have a $T_{\mathrm{c}}$ of $67.5^{\circ} \mathrm{C}$ for the heating cycle and $59.7{ }^{\circ} \mathrm{C}$ for the cooling cycle, ${ }^{13}$ while our results, using the same method present a $T_{\mathrm{c}}$ for the heating cycle of $61 \pm 3{ }^{\circ} \mathrm{C}$ and $55 \pm 2{ }^{\circ} \mathrm{C}$ for the cooling cycle, this represents $4-6{ }^{\circ} \mathrm{C}$ lower than that reported previously. The difference can be explained due to particle size and strain effect on our samples; it has to be noted that the microparticles shown here are formed by the accumulation of nanoparticles.

In the literature Lopez et al. reported the fabrication of $\mathrm{VO}_{2}$ nanoparticles using the ion implantation method, in their work it is demonstrated that the transition temperature it is decreased due particle size effects and moreover as a result of defects in $\mathrm{VO}_{2}$ that causes nucleation spots for the phase transition. ${ }^{32}$

Phase nucleation is reported to be due to vacancies, substitutions, etc. ${ }^{33}$ oxygen vacancies are usually reported in the literature as defects on nanostructure surfaces; ${ }^{34}$ therefore while the size of the particles decreased, the surface ratio increased, consequently the nucleation defect density is higher in smaller particles causing the diminution of the transition temperature in the as-prepared nanoparticles, compared to the as-prepared microparticles.

In Table 3 DSC measurements of critical temperatures for the mentioned $\mathrm{VO}_{2}(\mathrm{R})$ reported in the literature and in the present work are shown.

Tungsten doped $\mathrm{VO}_{2}(\mathrm{D})$ microparticles samples were synthesized in order to study the change in the transition temperature once the rutile phase is obtained after heat treatment of the prepared sample. It is well known in the literature that the addition of tungsten to the vanadium thermochromic samples decreases the transition temperature. In our case samples were doped with 2, 3 and 4 at\% of tunsgten(Iv) chloride. 
Table 3 Comparison of DSC transition temperatures for heating and cooling cycles of $\mathrm{VO}_{2}(\mathrm{R})$ (to $\mathrm{VO}_{2}(\mathrm{M})$ )

\begin{tabular}{|c|c|c|c|}
\hline Process & $T_{\mathrm{c}}$ heating cycle $\left({ }^{\circ} \mathrm{C}\right)$ & $T_{\mathrm{c}}$ cooling sample $\left({ }^{\circ} \mathrm{C}\right)$ & Hysteresis $\left({ }^{\circ} \mathrm{C}\right)$ \\
\hline $\mathrm{VO}_{2}(\mathrm{~B}) \rightarrow \mathrm{VO}_{2}(\mathrm{R})$ hydrothermal synthesis ${ }^{35}$ & 68.75 & 59.77 & 8.98 \\
\hline $\mathrm{VO}_{2}(\mathrm{D}) \rightarrow \mathrm{VO}_{2}(\mathrm{R})$ hydrothermal synthesis ${ }^{29}$ & 67.5 & 57.9 & 9.6 \\
\hline
\end{tabular}

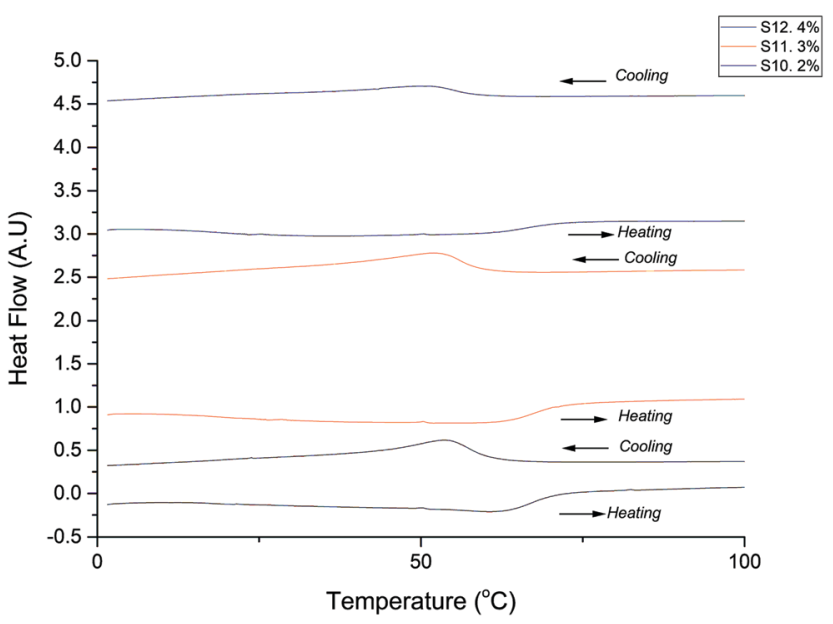

Fig. 6 DSC curves of tungsten doped $\mathrm{VO}_{2}(\mathrm{R})$ obtained via tungsten dope micro- $\mathrm{VO}_{2}(\mathrm{D})$ after heat treatment.

Fig. 6 shows the DSC of three tungsten doped (2, 3 and 4 at\%) $\mathrm{VO}_{2}(\mathrm{M})$ samples, obtained via $\mathrm{VO}_{2}(\mathrm{D})$. In all three samples the $T_{\mathrm{c}}$ for the heating cycle is at $62 \pm 1{ }^{\circ} \mathrm{C}$ and the $T_{\mathrm{c}}$ for the cooling cycle in all cases is at $52 \pm 1{ }^{\circ} \mathrm{C}$. It is surprising that there is no significant change in the transition temperature as expected. It appears as if pre-doping of $\mathrm{VO}_{2}(\mathrm{D})$ particles with $\mathrm{W}$ is not an effective method to lower the $T_{\mathrm{c}}$ in subsequently produced $\mathrm{VO}_{2}(\mathrm{M})$; our results in fact suggest that $\mathrm{W}$ is not incorporated into the $\mathrm{VO}_{2}(\mathrm{D})$ lattice using the hydrothermal approach used here, see the ESI, $\dagger$ for full details of $\mathrm{W}$ doping experiments.

As discussed above, $\mathrm{VO}_{2}(\mathrm{D})$ microparticle samples required annealing at $350{ }^{\circ} \mathrm{C}$ to obtain $\mathrm{VO}_{2}(\mathrm{R})$. However for $\mathrm{VO}_{2}(\mathrm{D})$ nanoparticles, a much lower annealing temperature is required. DSC illustrating the phase transitions occurring upon annealing under $\mathrm{N}_{2}$ of $\mathrm{VO}_{2}$ (D) nanoparticles is shown in Fig. 7. In the first heating cycle of the as made materials, the first significant feature in the DSC curve occurs at $163 \pm 2{ }^{\circ} \mathrm{C}$, where a strong endothermic peak is seen. This is assigned to the $\mathrm{VO}_{2}(\mathrm{D}) \rightarrow \mathrm{VO}_{2}(\mathrm{R})$ transition. No further transitions are seen upon heating up to $300{ }^{\circ} \mathrm{C}$. In the first cooling cycle, no feature is seen at around $163{ }^{\circ} \mathrm{C}$, showing that the phase transition observed in the heating cycle is irreversible. Upon further cooling, an exothermic peak is observed at $42 \pm 1{ }^{\circ} \mathrm{C}$; this is assigned to the $\mathrm{VO}_{2}(\mathrm{R}) \rightarrow \mathrm{VO}_{2}(\mathrm{M})$ transition. In the second heating cycle, the system displays typical thermochromic behaviour. An endotherm peak is now observed at $59 \pm 1{ }^{\circ} \mathrm{C}\left(\mathrm{VO}_{2}(\mathrm{M})-\mathrm{VO}_{2}(\mathrm{R})\right)$. No further signals are seen up to $300{ }^{\circ} \mathrm{C}$. In the second cooling cycle, an exothermic peak is again observed at $42 \pm 1{ }^{\circ} \mathrm{C}\left(\mathrm{VO}_{2}(\mathrm{R})-\mathrm{VO}_{2}(\mathrm{M})\right)$. It is noteworthy that in these samples the $\mathrm{VO}_{2}(\mathrm{D}) \rightarrow \mathrm{VO}_{2}(\mathrm{R})$ transition temperature of

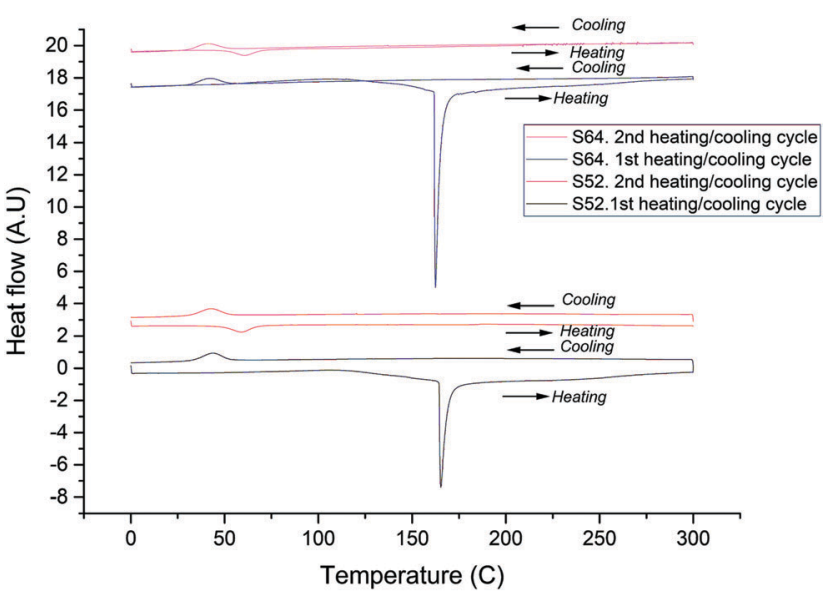

Fig. 7 DSC curves of $\mathrm{VO}_{2}(\mathrm{R})$ obtained via nano- $\mathrm{VO}_{2}(\mathrm{D})$ samples showing the transition from the $D$ to $R$ phase and then, the reversible thermochromic behaviour of $\mathrm{VO}_{2}(\mathrm{R})$.

$163{ }^{\circ} \mathrm{C}$ is significantly lower than that previously reported $\left(250{ }^{\circ} \mathrm{C}\right),{ }^{5}$ which we attribute to the small size of the particles. The thermochromic material thus produced also shows a lower MST temperature than expected from bulk vanadium dioxide. This has also been seen previously with nanoscale $\mathrm{VO}_{2} \cdot{ }^{25}$

\section{Conclusion}

$\mathrm{VO}_{2}(\mathrm{D})$ microparticles were synthesised using $\mathrm{NH}_{4} \mathrm{VO}_{3}$ and oxalic acid as a precursor and a reducing agent, respectively via a hydrothermal synthesis reaction. We demonstrate in this work that it is possible to obtain pure $\mathrm{VO}_{2}(\mathrm{D})$ with different morphologies by simply changing the $\mathrm{pH}$ of the starting solution using $\mathrm{NaOH}$ at $1 \mathrm{M}$ concentration. A phase transformation from $\mathrm{D}$ to $\mathrm{M}$ is possible at $350{ }^{\circ} \mathrm{C}$ under vacuum obtaining a pure monoclinic phase with MST reported at $61{ }^{\circ} \mathrm{C}$ for the heating cycle and at $55^{\circ} \mathrm{C}$ for the cooling cycle.

$\mathrm{W}$ doping of $\mathrm{VO}_{2}(\mathrm{D})$ microparticles was attempted, yet the MST temperature for each nominally doped sample was unchanged from undoped $\mathrm{VO}_{2}$, indicating that $\mathrm{W}$ doping of $\mathrm{VO}_{2}(\mathrm{D})$ followed by conversion into $\mathrm{VO}_{2}(\mathrm{R})$ does not appear to be successful.

$\mathrm{VO}_{2}$ (D) nanoparticles were synthesized using vanadium pentoxide and sulfuric acid as a precursor and a reducing agent respectively. The size of the obtained particles oscillates between 20 and $40 \mathrm{~nm}$. To obtain $\mathrm{VO}_{2}(\mathrm{M})$ in this case the heat treatment of the sample is required at $165^{\circ} \mathrm{C}$ for a few minutes under a nitrogen atmosphere. After the samples are heat 
treated a fully thermochromic sample is obtained with a MST for the heating cycle at $59{ }^{\circ} \mathrm{C}$ and $42{ }^{\circ} \mathrm{C}$ for the cooling cycle. This is the lowest $\mathrm{VO}_{2}(\mathrm{D}) \rightarrow \mathrm{VO}_{2}(\mathrm{R})$ transition temperature reported in the literature, and shows the importance of particle size on phase transition temperatures. In addition the reported MST temperature in this work for $\mathrm{VO}_{2}(\mathrm{M})$ nanoparticles obtained from $\mathrm{VO}_{2}(\mathrm{D})$ is lower than that reported for bulk $\mathrm{VO}_{2}$. We attribute this to the particle size and strain in nanoparticles of $\mathrm{VO}_{2}(\mathrm{R})$ produced from $\mathrm{VO}_{2}(\mathrm{D})$.

\section{References}

1 R. Molaei, R. Bayati, S. Nori, D. Kumar, J. T. Prater and J. Narayan, Appl. Phys. Lett., 2013, 103, 2-6.

2 C. Moffatt and A. Wigstein, Sol-gel synthesis of $\mathrm{VO}_{2}$ thin films and the effects of $W$ and Re doping, 2005.

3 H. Jerominek, F. Picard, N. R. Swart, M. Renaud, M. Lévesque, M. Lehoux, S. Castonguay, M. Pelletier, G. Bilodeau, D. Audet, T. D. Pope and P. Lambert, Proc. SPIE, 1996, 2746, 60-71.

4 C. V Subba, E. H. Walker, S. A. W. Sr, Q. L. Williams and R. R. Kalluru, Curr. Appl. Phys., 2009, 9, 1195-1198.

5 Y. Zhang and Y. Huang, Mater. Lett., 2016, 182, 285-288.

6 X. Juan, J. Ming, X. Wen, F. Rui and Y. Xin, Ceram. Int., 2016, 42, 7883-7887.

7 K. Zhao, L. Teng, Y. Tang and X. Chen, Ceram. Int., 2014, 40, 15335-15340.

8 Q. Wang, J. Pan, M. Li, Y. Luo, H. Wu, L. Zhong and G. Li, J. Mater. Sci. Technol., 2015, 31, 630-633.

9 Z. Chen, Y. Gao, L. Kang, C. Cao, S. Chen and H. Luo, J. Mater. Chem. A, 2014, 2, 2718.

10 M. J. Powell, R. Quesada-cabrera, A. Taylor, D. Teixeira, I. Papakonstantinou, R. G. Palgrave, G. Sankar and I. P. Parkin, Chem. Mater., 2016, 28, 1369-1376.

11 J. Zhu, Y. Zhou, B. Wang, J. Zheng, S. Ji, H. Yao, H. Luo and P. Jin, Appl. Mater. Interfaces, 2015, 7, 27796-27803.

12 Y. Gao, S. Wang, H. Luo, L. Dai, C. Cao, Y. Liu, Z. Chen and M. Kanehira, Energy Environ. Sci., 2012, 6104-6110.

13 Z. Song, L. Zhang, F. Xia and N. A. S. Webster, Inorg. Chem. Front., 2016, 3, 1035-1042.

14 D. Hagrman, J. Zubieta, C. J. Warren, L. M. Meyer, M. M. J. Treacy and R. C. Haushalter, J. Solid State Chem., 1998, 182, 178-182.

15 J. H. Park, J. M. Coy, T. S. Kasirga, C. Huang, Z. Fei, S. Hunter and D. H. Cobden, Nature, 2013, 500, 431-434.
16 Y. Zhang, X. Tan, C. Huang, C. Meng, Y. Zhang, X. Tan, C. Huang and C. Meng, Mater. Res. Innovations, 2016, 10, 295-302.

17 L. Liu, F. Cao, T. Yao, Y. Xu, M. Zhou, B. Qu, B. Pan, C. Wu, S. Wei and Y. Xie, New J. Chem., 2012, 36, 619.

18 L. Zhong, M. Li, H. Wang, Y. Luo, J. Pan and G. Li, CrystEngComm, 2015, 17, 5614-5619.

19 D. Louloudakis, D. Vernardou, E. Spanakis, S. Dokianakis, M. Panagopoulou, G. Raptis, E. Aperathitis, G. Kiriakidis, N. Katsarakis and E. Koudoumas, Phys. Status Solidi C., 2015, 860, 856-860.

20 Y. Shimizu, K. Nagase, N. Miura and N. Yamazoe, Jpn. J. Appl. Phys., 1990, 29, 1708-1711.

21 M. J. Powell, P. Marchand, C. J. Denis, J. C. Bear, J. A. Darr and I. P. Parkin, Nanoscale, 2015, 7, 18686-18693.

22 J. H. Son, J. Wei, D. Cobden, G. Cao and Y. Xia, Chem. Mater., 2010, 22, 3043-3050.

23 S. Y. Li, G. A. Niklasson and C. G. Granqvist, J. Appl. Phys., 2010, 108, 1-8.

24 C. Sanchez, J. Livage and G. Lucazeau, J. Raman Spectrosc., 1982, 12, 3-7.

25 B. Lei, W. Qin, G. Kang, C. Peng and J. Wu, J. Am. Ceram. Soc., 2015, 1633, 1626-1633.

26 H. Zhu, D. Yang, G. Yu and H. Zhang, Nanotechnology, 2006, 17, 2386-2389.

27 C. Wang, X. Wang, P. Gong and T. Yao, Chemosphere, 2016, 149, 358-365.

28 S. A. Corr, M. Grossman, Y. Shi, K. R. Heier, D. Stucky and R. Seshadri, J. Mater. Chem., 2009, 2, 4362-4367.

29 G. Z. Song, L. Zhang, F. Xia, N. A. S. Webster, J. Song, B. Liu, H. Luoa and Y. Gao, Inorg. Chem., 2016, 3, 1035-1042.

30 W. Li, S. Ji, Y. Li, A. Huang, H. Luo and P. Jin, RSC Adv., 2014, 4, 13026.

31 S. Rao, A. Artemenko, C. Labrugere and M. Miclau, J. Solid State Chem., 2014, 213, 79-86.

32 R. Lopez, T. E. Haynes and L. A. Boatner, Phys. Rev. B: Condens. Matter Mater. Phys., 2002, 65, 1-5.

33 L. Hongwei, L. Junpeng, Z. Minrui, T. S. Hai, S. C. Haur, Z. Xinhai and K. Lin, Opt. Express, 2014, 22, 30748-30755.

34 J. Jeong, N. Aetukuri, T. Graf, T. D. Schladt, M. G. Samant and S. S. P. Parkin, Science, 2013, 339, 1402-1406.

35 M. Li, F. Kong, Y. Zhang and G. Li, CrystEngComm, 2011, 13, 2204. 